\title{
SIMULATION DESIGN OF THE SPIRAL GROOVE PRECISION SEED-METERING DEVICE FOR SMALL GRAINS
}

\author{
Dongguang Zhang ${ }^{1}$, Yuming Guo \\ ${ }^{1}$ College of Engineering and Technology, Shanxi Agricultural University, Taigu 030801 \\ Shanxi Province, P. R. China \\ * Corresponding author, Address: College of Engineering and Technology, Shanxi \\ Agricultural University, Taigu 030801 Shanxi Province, P. R. China, Tel: +86-354- \\ 6288906, Fax: +86-354-6288906, Email: guoyuming99@sina.com
}

\begin{abstract}
At present, most of small grain crops such as millet and forage seeds are sown by external force feed in mainland China, which has some problems of wasting seeds, uneven seed distribution and so on. Therefore, it is needed to design a precise feed device for small grain corps. The author's of this paper established a three-dimensional model to design the spiral groove precision seed-metering device using Pro/Engineer. The movement simulation and clearance were tested between the seeding roller and the shell by mechanism module. According to the analysis results, the defaults of the feed device were modified, so that the model structure was optimized. The simulation results showed that this device is simple and suitable and suitable for the seeding requirements of small grains.
\end{abstract}

Keywords: $\quad$ seed-metering device, small grain crops, simulation design

\section{INTRODUCTION}

The fluted-roller metering system invented by Jethro Tull has been used on grain drills for over 300 years (Brown E, 2003). The system is a model of simplicity and has been sufficient for seeding small grains. Based on this system, the seed-metering device and the relevant technique have been

Please use the following format when citing this chapter:

Zhang, D. and Guo, Y., 2009, in IFIP International Federation for Information Processing, Volume 293, Computer and Computing Technologies in Agriculture II, Volume 1, eds. D. Li, Z. Chunjiang, (Boston: Springer), pp. 155-160. 
greatly improved and developed. But this traditional seed-metering device is still unable to implement precision seeding for small grain crops. The scholars all over the world have devoted themselves to develop a precision small grain crops seeding devices, which has better and better seeding accuracy to save seeds and improve the following cultivation work.

The study of seed-metering device for small grain crops began in the 1960s abroad. A very successful vacuum seeder for precision sowing of fine seeds was invented in 1967 (Gianini et al, 1967). A vacuum metering system was used for sowing cotton in 1970 (Hudspeth et al, 1970). A punch planter was designed and constructed for sugar beet using a wheel with six conical punches on the circumference (Jafari et al 1972). Fluid meter for cotton and sorghum were studied and the seeding efficiency was determined. (Lepori 1972). However, they did not investigate the seed metering uniformity of the system. The operational characteristics of the fluted-roller meter of a grain drill was designed (Jafari, 1991), he noticed the seed metering uniformity is impaired by the sudden release of the seed batches, especially at higher rates. To overcome this shortcoming, he considered to use multi-flight screws in a metering device for better uniformity.

Many practical progresses have been made in the research of precision seeding for corn wheat and other crops in China and some models have been manufactured for farmers. The study of precision seeding for small grains such as millet and forage has been started, however, the reliable machines are rarely seen. The millet and other small grain crops are mainly planted in the hilly areas of Shanxi Province China, which are the national production base. At present, most of small grain crops are sowed by manpower and animal power. This kind of traditional manual work is very difficult, consuming time and wasting seeds. The study of planting technology and equipment for small grain crops has been become an important and urgent program.

\section{THE DESIGN OF SPIRAL GROOVE SEED- METERING DEVICE}

Special-shaped spiral groove precision seed-metering device used for small grain crops is designed. The key point is to use cylindrical seeding roller with multi-head spiral grooves. The roller is housed and can not move along its axis. Seeds fall into the space orderly by gravity, and then seeds grouped in a line along the spiral grooves. Seeds move forward to the outlet of the metering system then fall into the tube. 


\subsection{The size and shape of spiral grooves}

The design concept of the spiral groove section is that: the cross section of the groove can accommodate only one seed and self-locking must be avoided between seeds. For different shape grains, comparative analysis of several section structures are as follows:
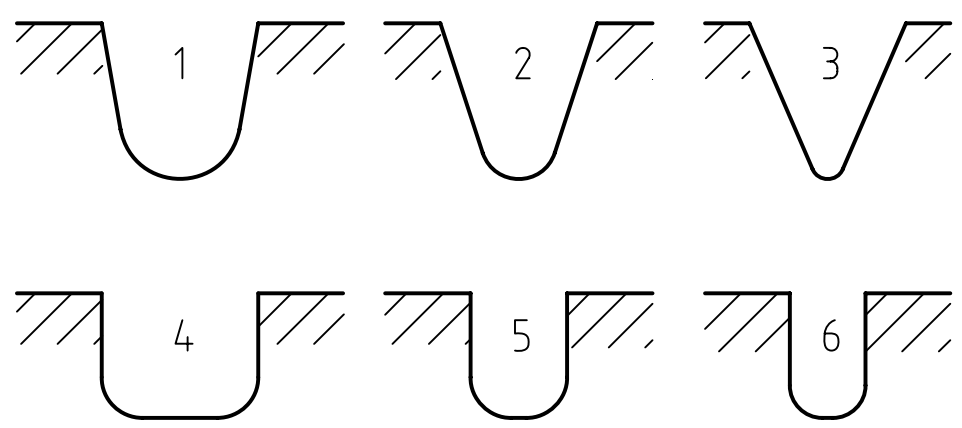

Fig.1: The structure of the spiral groove sections

The structure of the spiral groove sections are illustrated in Fig. 1. No.1, 2, 3 are the $\mathrm{V}$-shaped sections, No.4, 5, 6 are the rectangular sections. In order to avoid the self-locking in the spiral groove, the circular cornering is designed in the spiral groove bottom.

The width of the rectangular shape is larger to accommodate more seeds, so that higher friction exists among seeds. This situation may result in selflocking even blocking while the seeding roller is working. The V-shaped bottom is smaller than that of the rectangular. The friction is much lower among seeds, so the self-locking can be reduced efficiently. This type of bottom is stable for seeding performance. Therefore, the V-shaped bottom is chosen in the design; the size of spiral groove sections can be designed for different crops.

\subsection{The inclination and numbers of spiral grooves}

The diameter of the roller and the pitch of the spiral groove are selected as $50 \mathrm{~mm}$ and $32 \mathrm{~mm}$ respectively. In this condition, the inclination meets demand. Seeds can complete axial movement.

Spiral groove number influence the seeding uniformity. We increase the numbers to improve it. The spiral groove seeding roller, which spiral number is 3, is shown in Fig. 2. 


\subsection{The design and calculation of the shell}

It is important to design the size of inlet, outlet and the internal diameter of the shell. Based on the measured values of material physical characteristics, the key points are: (1) when the corner angle of the inlet gate is $90^{\circ}$, it is good for falling seeds, (2) the rectangular inlet can improve the ability of filling and separating seeds, (3) the axial distance between inlet and outlet is two thirds of the pitch. The width of outlet is designed as $10 \mathrm{~mm}$. In order to facilitate the seed-filling, an adjustable flap is installed on the inlet. The shell 3D model is shown in Fig. 3.

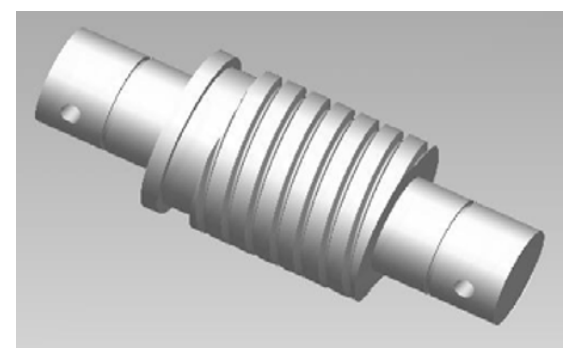

Fig.2.The spiral groove seeding shaft

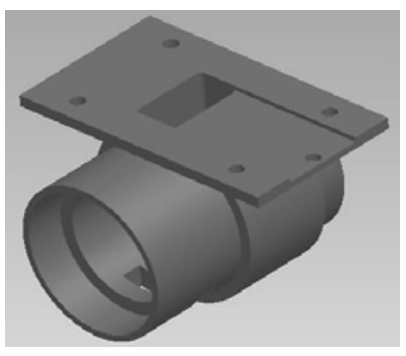

Fig.3. The seed-metering device shell

\section{THE ASSEMBLY AND SIMULATION OF SEED- METERING DEVICE MODEL}

\subsection{The assembly of device model}

The spiral groove precision seed-metering device is made of the seeding roller, the shell and the hopper. The assembly process is (1) fix the shell in the assembly, and choose the connect type between the shell and the seeding roller by Pin, (2) place hopper, bolts and nuts with constraints of Align and Mate, (3) assemble axletrees and snap rings with fully constrained, then complete the assembled model. The explode view of spiral groove seedmetering device model is illustrated in Fig. 4. 


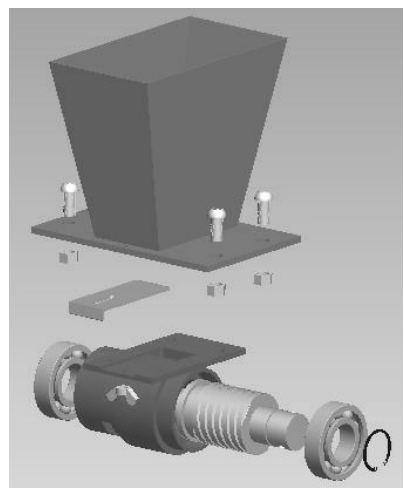

Fig. 4 The explode view of seed-metering device

\subsection{The simulation and analysis of roller model}

When the assembly is completed, we enter the Mechanism module: (1) flip the axis of the seeding roller as a new servo motor and define rotary speed, (2) choose kinematics as an analysis type, define length and rate in the graphical display window and run the analysis, (3) drag the playback button to observe the situation of kinematical pairs, (4) click mode button to check global interference among components, (5) generate analysis graphics of measure results and optimize parameters. By monitoring, there is no interference among all components. The movement simulation analysis is shown in Fig. 5.

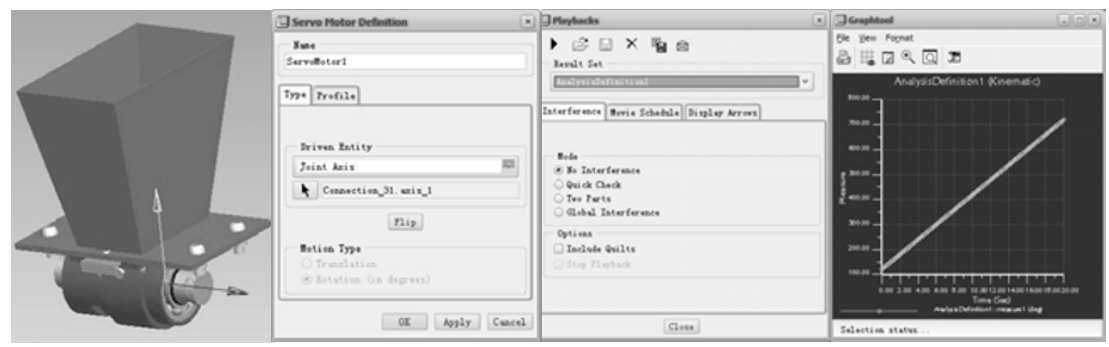

Fig.5 The movement simulation analysis

\section{CONCLUSION}

Based on Pro/E, the 3D modeling and movement simulation of spiral groove precision seed-metering device for small grain crops is processed and 
analyzed. The results showed that components have no interference; the structural design is reasonable. Refer to dynamics question, as moisture, maturity and geometrical shape of seeds and other organisms are uncertain, it is hard to get reliable results from simulation. Therefore, tests and multiple experiments of prototypes are necessary steps. Based on the simulation results and drawings of this study, sample machine is being constructed. Primary test of the sample machine indicated that the simulation designing was reliable.

\section{ACKNOWLEDGEMENTS}

Funding for this research was provided by Shanxi Provincial Department of Technology (P. R. China). The first author is grateful to Professor Guo Yu-ming, Professor Zhang Wen-huan for directing him all the time. Thanks to $\mathrm{Ms}$. Wu Ya-li for helping me in studying and working, also thanks to my parents for all their supporting and understanding to my study.

\section{REFERENCES}

Brown E. Sowing seeds for the agricultural revolution: Jethro Tull. Implement \& Tractor, 2003:1674-1741.

Gianini G R, Chancellor W J, Garrett R E. Precision planter using vacuum for seed pickup. Transaction of the ASAE, 1967,10(2): 607,614.

Hudspeth E B, Wanjura D F. A planter for precision depth and placement of cotton. Transaction of the ASAE,1970,13(2): 153-155.

Jafari J F. A study of the metering of free following particulate solids using multi-flight screw. Proceedings of Institution of Mechanical Engineers,1991,(205): 113-120.

LePori W A, Porterfield J G, Fitch Jr E C. Fluidic control of seed metering. Transaction of the ASAE, 1972,17(3): 463-465.

M R Maleki, J F Jafari,M H Raufat et al. Evaluation of Seed Distribution Uniformity of a Multi-flight Auger as a Grain Drill Metering Device, Biosystems Engineering,2006,94(4): 535-543. 